\title{
Numerical Analysis and Risk Assessment on Face Stability of Large-Diameter Tunnels
}

\author{
Qunfang $\mathrm{Hu}^{1}$ and Hongwei Huang ${ }^{2}$ \\ ${ }^{1}$ Shanghai Institute of Disaster Prevention and Relief, Tongji University, Shanghai, China \\ huqunf@mail.tongji.edu.cn \\ ${ }^{2}$ Department of Geotechnical Engineering, Tongji University, Shanghai, China \\ huanghw@mail.tongji.edu.cn
}

\begin{abstract}
For the two types of shield tunneling such as Slurry and EPB shield the stability of tunnel face depends on the prevailing support pressure. The support pressure at the tunnel face has to be applied to a value that gives as well sufficient safety against a collapse of the tunnel face as the against uplifting. The paper aims at a better understanding of the mechanics of face failure for those lager-diameter tunnels. And some different determination methods of the applied support pressure are compared and given a risk assessment, which are illustrated their application by numerical analysis in the Yangtze River Tunnel of Shanghai.
\end{abstract}

Keywords: face stability, risk assessment, numerical analysis, large-diameter tunnel.

\section{Introduction}

With underground excavations and construction works progress into much larger diameter tunnels and more complex geological environments, Slurry shield and EPB tunneling have been successfully applied worldwide in recent years, which allow the control the surface settlement and limit the risk of tunnel face failure through the continuous support the face. However, face instabilities may occur under extremely unfavorable geological conditions, especially some lager-diameter tunnels like the Yangtze River Tunnel of Shanghai whose outside diameter is about $15.0 \mathrm{~m}$.

As is known, Peck [1] introduced the one of main issues to be addresses for the design and construction of tunnels: stability of the opening during construction with particular attention to the tunnel face stability. The stability of tunnel face is of paramount importance for construction the lager-diameter tunnel works. Several approaches have been developed to analyze and calculate the support pressure of tunnel face over the past thirty years. Early works on face stability were concerned with tunnels constructed in clays (Broms and Bennermark [2]; Peck [1]). Then a more theoretical approach based on limit analysis was presented for clays by Davis et al [3]. Within the framework of limit analysis, some lower bound solutions were presented to analyze tunneling in sandy ground by Muelhaus [4], Leca and Panet [5] and Leca and Dormieux [6]. And the approaches were checked against model tests performed with Fontainebleau sand in the centrifuge of the Laboratoire Central des Ponts et Chaussées (LCPC) in Nantes, France (Chambon and Corté [7,8] ). Another approach, 
taking full account of the 3-dimensional geometry at the tunnel face, was proposed by Anagnostou and Kovári $[9,10,11]$, using limit equilibrium principles based on the Horn [12] (see figure 1) model. Recent developments allowed the computational methods of tunnel face support pressure were proposed and performed by many researchers, Chen Z.L. [13], W. Broere [14], Vermeer P.A.\& Ruse N. [15].

There are so many methods for calculating the support pressure of tunnel face, and it is not easily to select the best one for design and construction large-diameter tunnel. The paper aims at a better understanding of the mechanics of face failure for those large-diameter tunnels by 3-Dimensional numerical simulation. And some different determination methods of the applied support pressure are compared here and given a risk assessment, which are illustrated their application by numerical analysis in the Yangtze River Tunnel of Shanghai.

\section{Different Computational Methods on Support Pressure of Tunnel Face}

In order to analyze the mechanics of face failure for those large-diameter tunnels by 3-D numerical simulation, 6 different computational methods were introduced as follows.

(1) The computational model of passive earth pressure [16]

(2) The computational model of earth pressure at rest [16]

(3) The computational model of active earth pressure [16]

(4) The computational model of Chen Z.L. [13]

$$
p_{z}=(0.6 \sim 0.7) \tan ^{2}\left(\frac{\pi}{4}-\frac{\phi^{\prime}}{2}\right)\left(\sigma_{v}-u\right)+u
$$

Where $u$ is the pore water pressure, and $\varphi^{\prime}$ is soil effective friction angle.

(5) The computational model of Ruse. N. [15]

$$
p_{R}=-c^{\prime} \cot \varphi^{\prime}+\gamma D\left(\frac{1}{9 \tan \varphi^{\prime}}-0.05\right)
$$

Where $c^{\prime}$ and $\varphi^{\prime}$ are soil effective cohesion and soil effective friction angle respectively, $\gamma$ is the unit soil weight at the depth of tunnel axis, and $D$ is tunnel diameter.

(6) The computational method of the minimal support pressure based on the Multilayered Wedge model

To construct a wedge stability model, as sketched in Fig.1, which could handle heterogeneous soil conditions by Anagnostou and Kovári $[9,10,11]$, the horizontal slice model described by Walz [17] for slurry-filled trenches might serve as a starting point. The failure wedge is subdivided in $N$ smaller bodies by W. Broere [14], see Fig. 2, possibly of different thickness, inside each of which the soil conditions are homogeneous. The soil conditions would vary between these slices, as may the wedge angle $\theta_{i}$ between the $i$ th slice's slanted failure plane and the horizontal. The conditions of horizontal and vertical equilibrium could lead to calculate the minimal support pressure as follows. 

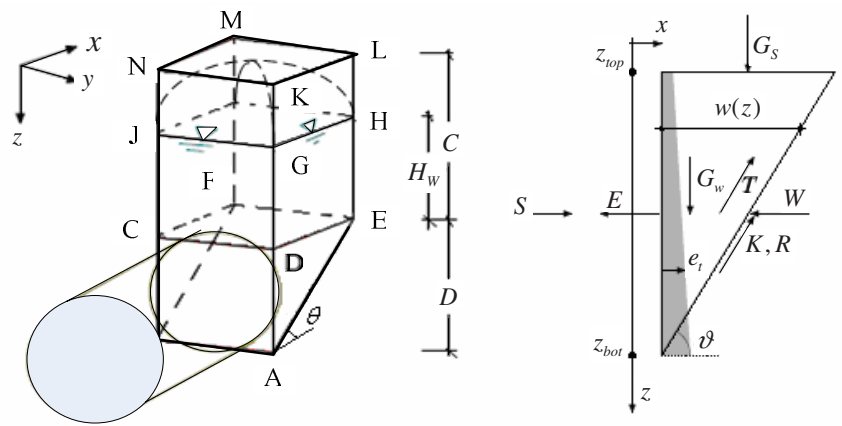

Fig. 1. Wedge-loaded model of three-dimensional tunnel face failure mechanism by soil silo

Each slice $i$ is loaded by the resulting forces from the slice above $(i-1)$ and below $(i+1), Q_{a}^{(i)}$ and $Q_{b}^{i}$ respectively, the effective weight of the slice itself $G_{w}^{i}$ and an overburden force $G_{s}^{i}$. At the slanted failure plane there is a cohesive force $K^{(i)}$ acting parallel to the plane, as well as a friction force $R^{(i)}$, which results from the normal force $N^{(i)}$, working perpendicular to the failure plane. The side faces of the wedge are each assumed to be loaded by the shear force $T^{(i)}$, which act in the same direction as $K^{(i)}$, against the deformation direction of the wedge. Force equilibrium will yield the effective earth force $E^{(i)}$ at the face which, combined with the water force $W^{(i)}$, is equal to the support force $S^{(i)}$.

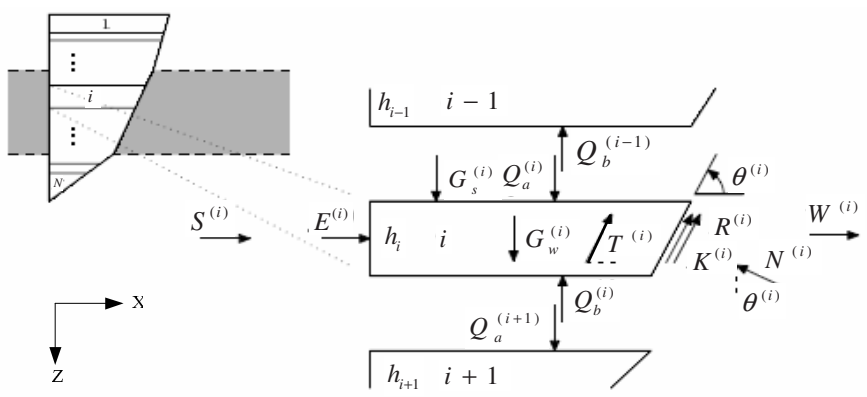

Fig. 2. Multilayered Wedge model of three-dimensional tunnel face failure for calculating the minimal support pressure

$$
\begin{gathered}
p_{\min }=4 \cdot S /\left(\pi \cdot D^{2}\right), S=E+W \\
E=-\frac{\xi_{-}^{\prime}}{\xi_{+}^{\prime}}\left[G_{S}+G_{w}+\sum_{i=1}^{N} \frac{1}{\xi_{-}^{(i)}}\left(2 T^{(i)}+K^{(i)}\right)\right], \quad \frac{\xi_{+}^{\prime}}{\xi_{-}^{\prime}}=\frac{1}{N} \sum_{i=1}^{N} \frac{\xi_{+}^{(i)}}{\xi_{-}^{(i)}}
\end{gathered}
$$


Where all computational parameters are given in Fig. 2, and some functions were explained [14] and [16].

\section{Numerical Analysis Model and Risk Assessment}

\subsection{The Model of Numerical Analysis}

According to all above computational methods of support pressure of tunnel face, some different support pressure of tunnel face may be calculated. When largediameter tunnels were designed and constructed, the factual support pressure at the tunnel face had to be applied to a value that gives as well sufficient safety against a collapse of the tunnel face as the against uplifting. So the appropriate support pressure should be selected through analyzing the mechanics of face failure for large-diameter tunnel. In order to analyze the mechanics of tunnel face failure through numerical simulation, there were some problems which needed to be considered in advance.

(1) The method of numerical analysis. There are so many softwares such as ANSYS, ABAQUS, Plaxis and FLAC3D etc., which could be used to simulate and analyze the process of tunneling. Because the method of numerical analysis aimed at a better understanding and simulating of the mechanics of face failure for those lagerdiameter tunnels, the selected software should calculate the 3-D tunnel built of soil that undergo large deformation, plastic flow and face collapse. As is known, FLAC3D offers an ideal analysis tool for solution of 3-D problems in geotechnical engineering. And it could accord with the requirement of numerical analysis for engineering mechanics computation of tunnel face instability.

(2) The criterion to judge the face failure of tunnel. The key problem is to establish a criterion for judging the plastic or collapse condition of tunnel face. There are two criteria [18], one is to set the non-convergence of force and displacement of tunnel face as a judgment of numerical analysis; and the other is to set the plastic flow or the yield stress state as determining the face failure condition. After considered that the distribution of plastic zone was influenced by many factors such as Poisson's ratio, flow rule, etc, non-convergence of displacement in numerical analysis program could be taken as a suitable evaluating criterion for estimating the tunnel face failure.

(3) How to apply the support pressure to tunnel face. When tunnel face was excavating by slurry shield or EPB, the force distribution of in-suit tunnel face was trapeziform from the top to bottom of tunnel. So how to apply the support pressure to balance the in-suit earth pressure is a big problem. There are two application modes, one is to apply the support pressure to balance the earth pressure of tunnel face at the center of tunnel axis, and the other is to apply the support pressure to balance the earth pressure of tunnel face at the point of composition forces of tunnel face. Because the numerical simulation was to analyze the face stability of large-diameter tunnel, the latter mode was selected as a application mode of support pressure.

\subsection{Risk Assessment}

During the excavation of tunnel face, the distribution of earth pressure would change with tunneling. The face stability was a dynamic condition (see Fig.3). That is, the face stability would be undergone from a stable state to limit equilibrium and to instability even face collapse. So the risk about face stability of large-diameter tunnel 
could be assessed through the criterion for judging the face failure with the ratio of support pressure to vertical earth pressure at the centre of tunnel face.

$$
\lambda=p / \sigma_{v}
$$

Where $p$ is the support pressure at tunnel face, and $\sigma_{v}$ is the vertical earth pressure at the centre of tunnel face.

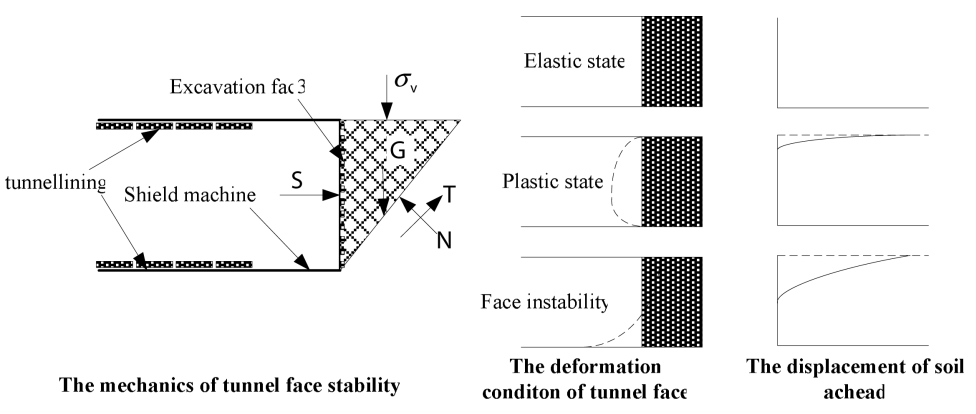

Fig. 3. The face stability condition and displacement of tunneling when the support pressure was decreased gradually

\subsection{Case Study}

Yangtze River tunnel is the south crossing way from Pudong to Changxing Island in Shanghai. This tunnel has about a $7.5 \mathrm{~km}$ in length and $15 \mathrm{~m}$ in outside diameter. In order to illustrate the method of numerical analysis and risk assessment, the tunnel alignment pile K0+589 was studied [16]. Based on the geology investigation data and tunnel structure design, the computational parameters of soil and tunnel at No $\mathrm{K} 0+589$ are shown in Table 1 .

Table 1. The computational parameters of soil at Pile No. K0+589

\begin{tabular}{cccccccccc}
\hline \multirow{2}{*}{ Soil type } & thickness & $\gamma$ & $c$ & $\varphi$ & $c^{\prime}$ & $\varphi^{\prime}$ & $q_{\mathrm{u}}$ & $E_{\mathrm{s}}$ & $K_{0}$ \\
\cline { 2 - 9 } & $\mathrm{m}$ & $\mathrm{kN} / \mathrm{m}^{3}$ & $\mathrm{kPa}$ & & $\mathrm{kPa}$ & & $\mathrm{kPa}$ & $\mathrm{MPa}$ & \\
\hline (2) $_{3}$ & 4 & 18.7 & 8 & 27 & - & - & - & 10.84 & - \\
$(3)_{1}$ & 3.5 & 17.5 & 13 & 12.5 & 8 & 30.3 & 43 & 3.27 & 0.57 \\
$(3)_{2}$ & 2.5 & 18.3 & 7 & 28.5 & - & - & - & 9.06 & - \\
$(4)$ & 16.5 & 16.9 & 14 & 10.5 & 10 & 26.8 & 52 & 2.62 & 0.63 \\
$(5)_{1}$ & 1.2 & 17.3 & 16 & 12 & 15 & 25.2 & 58 & 3.19 & 0.61 \\
$(5)_{2}$ & 17.3 & 18 & 12 & 22 & - & - & - & 5.99 & 0.38 \\
(7) $_{1-2}$ & 10.45 & 18.2 & 12 & 24 & - & - & - & 5.86 & 0.37 \\
\hline
\end{tabular}

The different support pressures of large-diameter tunnel face were calculated by all above methods. And the deformation of the large-diameter tunnel could be studied by the different support pressure using the software Flac3D. And the risk assessment [19] could be given by the ratio of support pressure to vertical earth pressure at the centre of tunnel face shown as Table 2. 
Table 2. Risk assessment of different support prrssure applied on the tunnel face

\begin{tabular}{ccccccc}
\hline Support & $p_{\mathrm{p}}$ & $p_{0}$ & $p_{\mathrm{a}}$ & $p_{\mathrm{z}}$ & $p_{\mathrm{R}}$ & $p_{\text {min }}$ \\
pressure & & & & & & \\
\hline$p / \mathrm{kPa}$ & 473.356 & 202.891 & 197.519 & 91.417 & 65.804 & 51.75 \\
$\lambda=p / \sigma_{\mathrm{v}}$ & 1.56 & 0.67 & 0.65 & 0.30 & 0.22 & 0.17 \\
Risk class & serious & insignificant & considerable & serious & serious & severe \\
\hline
\end{tabular}

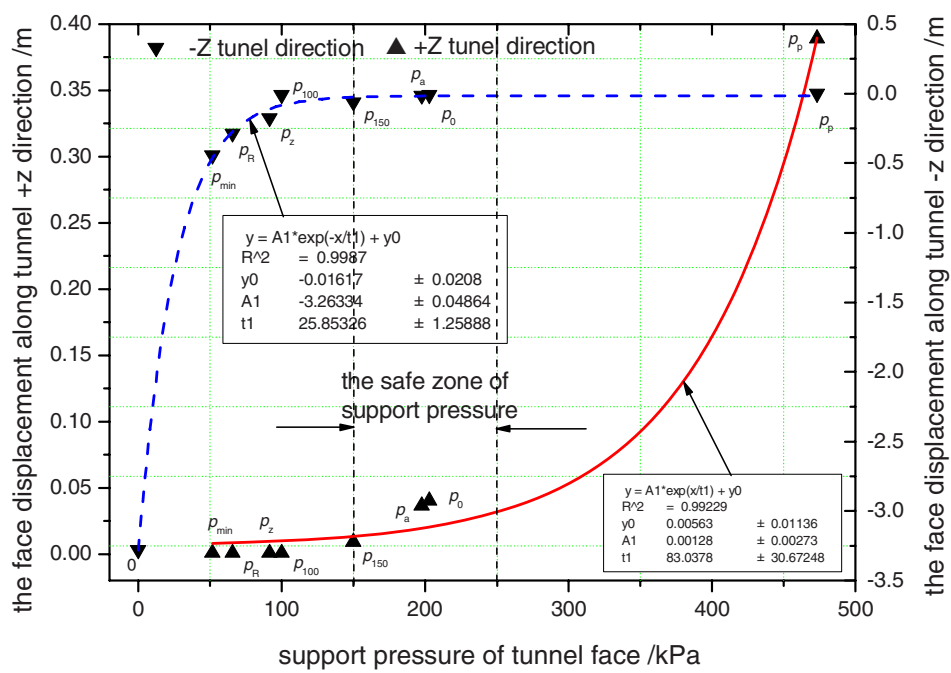

(a) the relation of displacement and support pressure of tunnel face

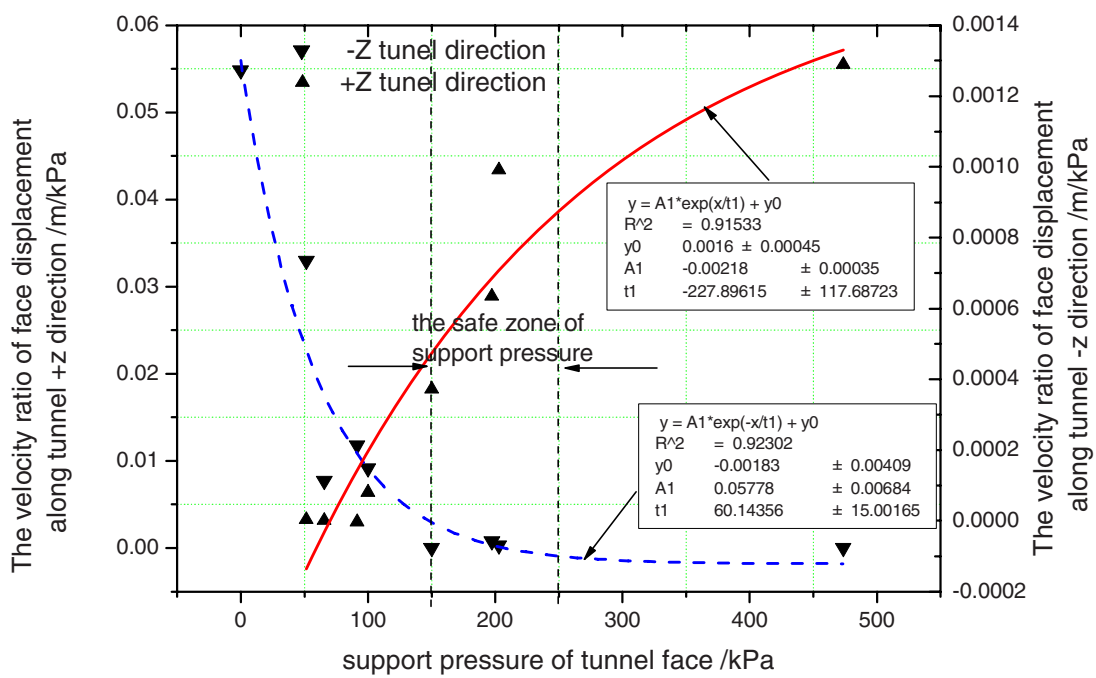

(b) the relation of displacement velocity and support pressure of tunnel face

Fig. 4. The relation of displacement and support pressure of tunnel face 
As the support pressure of tunnel face was decreased from $p_{\mathrm{p}}$ to $p_{0}$, the $+\mathrm{z}$ direction displacement along tunnel alignment was also decreased, otherwise, the $-\mathrm{z}$ direction displacement along tunnel alignment was increased (See Fig.4 (a)). When the support pressure was decreased from $p_{0}$ to $p_{\min }$, the $+\mathrm{z}$ direction displacement along tunnel alignment was still reduced to $0 \mathrm{~m}$, simultaneity, the $-\mathrm{z}$ direction displacement along tunnel alignment was increased the maximum, that is face collapse or instability when support pressure was null. The relation of displacement velocity and support pressure of tunnel face was shown in Fig.4 (b).

When the large-diameter was excavated by shield machine, the safety support pressure could be estimated by the displacement velocity of tunnel face to which was applied different support pressure. And the safe zone of support pressure of pile No.K0+589 was shown in Fig.5 (a) and Fig.5 (b).

\section{Conclusions}

(1) There were so many method which could be used to calculate the support pressure of large-diameter, and the actual support pressure was a value that gave as well sufficient safety against a collapse of the tunnel face as the against uplifting. So it is essential that the mechanics of face stability should be studied before the design and construction. And the method of numerical analysis and risk assessment could provide a new approach to determinate the safe support pressure.

(2) The face stability of tunnel was a dynamic process when the support pressure was changed during shield tunneling. The numerical analysis could give an elaborate simulation of the displacement process while the support pressure was decreased gradually. Compared the displacement and displacement velocity of different support pressure, the risk of tunnel face stability may be assessed simultaneity. And the risk management of tunnel construction should also be paid much attention to consider and adopt when the large-diameter tunnel was excavating.

Acknowledgments. This study was funded by the Program for New Century Excellent Talents in University under Education Ministry of China and Shanghai Municipal Science and Technology Commission (No.04dz12021), here great thanks should be given to them.

\section{References}

1. Peck, R.B.: Deep excavations and tunneling in soft ground. Proceedings 7th International Conference Soil Mechanics and Foundation Engineering, Mexico, State-of-the-Art Volume (1969) 225-290

2. Broms, B.B. (ed.): Stability of Clay at Vertical Openings. ASCE Journal of the Soil Mechanics and Foundation Division, SM1 (1967) 71-94

3. E. H. Davis (ed.): The stability of shallow tunnels and underground openings in cohesive material, Geotechnique, Vol.30, No.4 (1980)397-416

4. H. B. Muelhaus: Lower bound solutions for circular tunnels in two or three dimensions, Rock Mech. Rock Engng., Vol.18 (1985) 37-52 
5. Leca, E. and Panet, M: Application du calcul à la rupture à la stabilité du front de tailled'un tunnel. Revue Française de Géotechnique (1988) 5-19

6. Leca, E. (ed.): Upper and lower bound solutions for the face stability of shallow circular tunnels in frictional material. Géotechnique, Vol. 40, No.4 (1990) 581-606

7. Chambon, P. and Corté, J.F.: Stabilité du front de taille d'un tunnel faiblement enterré:modélisation en centrifugeuse. Proc. Int. Conf. Tunnelling and Microtunnelling in Soft Ground:From field to theory, Paris (1989) 307-315

8. Chambon, P. and Corté, J.F.: Shallow tunnels in cohesionless soil: stability of tunnel face. ASCE Journal of Geotechnical Engineering, Vol.120, No.7 (1994)1148-1165

9. Anagnostou, G.: A Model for Swelling Rock in Tunnelling. Rock Mechanics and Rock Engineering, Vol. 26, No. 4 (1993) 307-311

10. Anagnostou, G. and Kovàri, K.: Face Stability in Slurry and EPB Shield Tunneling. Proceedings International Symposium Geotechnical Aspects of Underground Construction in Soft Ground, London, 15-17 April 1996, R.J. Mair \& R.N. Taylor Eds. (1996a) 453-458

11. Anagnostou, G. and Kovàri, K.: Face Stability Conditions with Earth-Pressure-Balanced Shields. Tunnelling and Underground Space Technology, Vol. 11, No. 2 (1996b) 165-173

12. Horn, M. Alagutak homlokbiztositására ható vizszintes földnyomásvizsgálat néhány erdménye. Landeskonferenz der ungarischen Tiefbauindustrie,Budapest (1961)

13. Chen Z.L., (ed.): Experimental study on stability of tunnel excavation surface in sand foundation by slurry shield method, Vol. 18, No.5 (2001)53-55

14. W. Broere. Tunnel Face Stability \& New CPT Applications. PhD thesis, Delft University of Technology, Delft (2001)

15. Vermeer P.A., (ed.): Tunneling heading stability in drained ground. Felsbau (2002) 8-18

16. Q.F.Hu. Risk Analysis and Its Application for Tunnel Works based on Research of Stratum and Soil Spatial Variability. PhD thesis, Tongji University, China (2001)

17. B. Walz, J. (ed.): Berechnung und Ausf uhrung. Technical report, Bergische Universit"at Gesamthochschule Wuppertal (1983)

18. ZHAO Shang-yi (ed.): Slope safety factor analysis by strength reduction FEM. Chinese Journal of Geotechnical Engineering, Vol.24, No. 3 (2002) 343-346

19. D.E. Søren (ed.): Guidelines for the Tunneling Risk Management [J]. Tunneling and Underground Space Technology, Vol. 19, Issue 3, May (2004) 217-237 